\title{
Article
}

\section{Self-Piling Silicate Rods and Dendrites from High Aspect-Ratio Clay Platelets}

Chih-Wei Chiu, Chien-Chia Chu, Shenghong A. Dai, and Jiang-Jen Lin

J. Phys. Chem. C, 2008, 112 (46), 17940-17944 • DOI: 10.1021/jp806768v • Publication Date (Web): 28 October 2008

Downloaded from http://pubs.acs.org on December 28, 2008

\section{More About This Article}

Additional resources and features associated with this article are available within the HTML version:

- $\quad$ Supporting Information

- $\quad$ Access to high resolution figures

- $\quad$ Links to articles and content related to this article

- Copyright permission to reproduce figures and/or text from this article

\section{View the Full Text HTML}




\title{
Self-Piling Silicate Rods and Dendrites from High Aspect-Ratio Clay Platelets
}

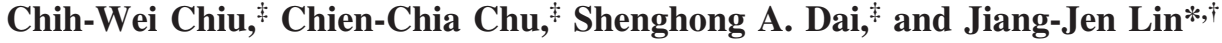 \\ Institute of Polymer Science and Engineering, National Taiwan University, Taipei 10617, Taiwan, and \\ Department of Chemical Engineering, National Chung Hsing University, Taichung 40227, Taiwan
}

Received: July 29, 2008; Revised Manuscript Received: September 5, 2008

\begin{abstract}
We observed the formation of unique rod-like microstructures by self-assembling of random mica platelets with a high aspect-ratio and counterion charged. The platelets are polydisperse with dimensions of 300-1000 $\mathrm{nm}$ in width and $1 \mathrm{~nm}$ in thickness and are prepared from the exfoliation of layered synthetic-fluorinatedmica. These platelets of polygon shape are characterized by transmission electron microscopy and atomic force microscopy. When finely dispersed in water followed by controlled evaporation, the randomized silicate platelets self-align into a rod-like morphology. The restructuring force is attributed to the intensive attraction of surface charges on high aspect-ratio platelets. The resulting thin platelets tend to self-align in a sizeselective manner through face-to-face piling into rod-like microstructures of 3-20 $\mu \mathrm{m}$ in length and 300-1000 $\mathrm{nm}$ in diameter (observed by field emission-scanning electron microscopy). The self-assembled rods, under an ultrasonic treatment, may further rearrange into fern-leaf dendrites via the process of fragmentation and restacking. The sequential transformation of platelet microstructures in a hierarchical manner allows a morphological manipulation for constructing patterns of regularity.
\end{abstract}

\section{Introduction}

Recent advances in nanomaterial applications have ranged from nanocomposites ${ }^{1,2}$ to optoelectronic devices ${ }^{3,4}$ and biomedical materials. ${ }^{5,6}$ A great deal of effort has been devoted to the synthesis and manipulation of new nanomaterials by different methods such as electron-beam induction, ${ }^{7}$ electrochemical deposition, ${ }^{8}$ thermal evaporation, ${ }^{9}$ and surfactant-assisted reduction. ${ }^{10}$ Various geometric shapes including nanospheres, ${ }^{11}$ -tubes, ${ }^{12}$-fibers, ${ }^{13}$-rings, ${ }^{14}$-plates, ${ }^{15}$ etc. were reported. These inorganic self-assemblies may exhibit unique physical and chemical properties. ${ }^{16-18}$

The smectite clays with high aspect-ratio and surface ionic charges are abundant in nature but seldom reported for their self-assembling behaviors, perhaps due to their overwhelming attracting force for irregular aggregation and difficult manipulation. ${ }^{19,20}$ For the similar reason, randomization or exfoliation of these silicate layer structures into finely dispersed platelet individuals is not an easy task. Conventionally, the layered clay stacks may be randomized but generally in the presence of organic polymer matrices such as in a clay/polymer nanocomposite. For example, the fine dispersion of the montmorillonite clays in the host polymeric matrix can be achieved through a two-step process: organic surfactant intercalation followed by exfoliation of the layered structure in polymer matrices. Intercalation can expand the silicate platelet gallery spacing up to $20-40 \AA$ from the pristine $12 \AA$. The surfactants for the ionic exchange intercalation are generally cationic organics such as fatty ammonium salts, ${ }^{21,22}$ alkyl phosphonium salts, ${ }^{23,24}$ and polymeric ammonium salts. ${ }^{25,26}$ Randomization or exfoliation of the layered clay is achieved by the process of reactive chemical compounding or by intensive melt mixing with the target polymers. ${ }^{27-29}$

* To whom correspondence should be addressed. Tel: +886-2-33665312. Fax: +886-2-3366-5237. E-mail: jianglin@ntu.edu.tw.

${ }^{\dagger}$ National Taiwan University.

¥ National Chung Hsing University.
Among the natural smectite clays such as montmorillonite (MMT), the synthetic fluorinated mica (Mica) has a similar layered structure bound by ionic bridges of counter metal ions in the primary stack but with a larger platelet size than MMT. The synthetic mica in primary unit has a well-defined structure with a dimensional range of 300-1000 nm, a $1 \mathrm{~nm}$ in thickness for each layer and an average of 4-6 platelets in one stack. ${ }^{30}$ Previously, we have demonstrated an exfoliative process that allows the randomization of the synthetic mica layered structure by using branched polyamine quaternary salts. ${ }^{31}$ Randomized mica platelets in water suspension, originally designed for promoting the physical properties of epoxy nanocomposite, ${ }^{32}$ can also be isolated. The self-assembling properties for the amine-modified layered Mica stacks were found to form various orderly structures. For example, we have reported the formation of rods, rod-bundles, and dendrite arrays. ${ }^{33}$ Here, we further reveal the hierarchical manner of self-assembling for the randomized mica platelets in forming unique morphology of microscale arrays.

\section{Experimental Section}

Materials. The synthetic fluorinated mica (Mica, SOMASIF ME-100), a layered silicate clay with chemical compositions of Si (26.5 wt \%), Mg (15.6 wt \%), Al (0.2 wt \%), Na (4.1 wt $\%), \mathrm{Fe}(0.1 \mathrm{wt} \%)$, and $\mathrm{F}(8.8 \mathrm{wt} \%)$, was obtained from COOP Chemical Co. (Japan). The Mica has a generic structure of 2/1 layered silicate/aluminum oxides with two tetrahedron sheets sandwiching an edge-shared octahedral sheet. The clay, obtained as an aggregated form at average particle size of $5 \mu \mathrm{m}$, has an exchangeable amount of $\mathrm{Na}^{+}$counterions at cationic exchange capacity (CEC) of 120 mequiv/100 g.

Exfoliation of Layerly Stacked Mica into Random Platelets in Water Suspension. The exfoliation of smectite clays and the fundamental properties of these silicate hybrids have been reported in our laboratories previously. ${ }^{31,32,34}$ Silicate platelets dispersed in aqueous medium were purified by a solvent extraction process. The isolated Mica platelets were character- 

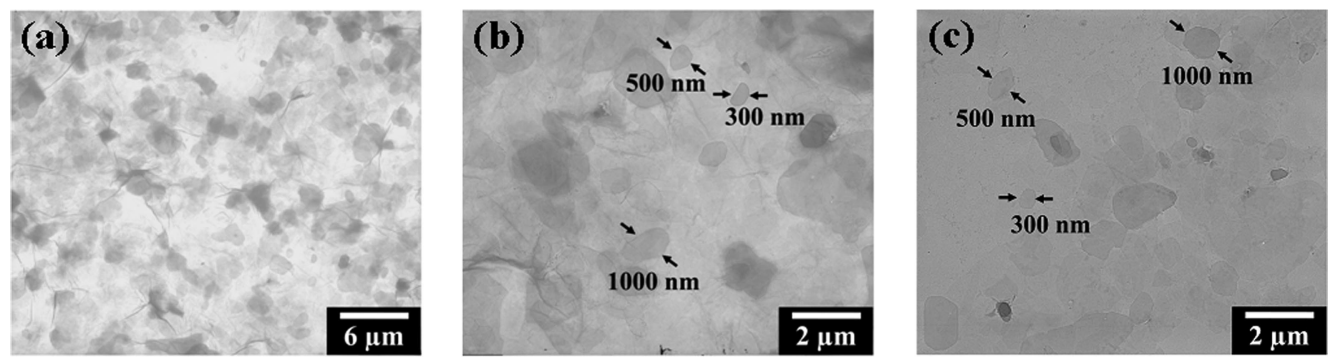

Figure 1. TEM micrographs of individual mica platelets suspension of different concentrations on air-dried copper grid, (a and b) $10^{-1}$ wt $\%$ at different magnifications and (c) $10^{-3} \mathrm{wt} \%$.

ized by X-ray powder diffraction (XRD), thermal gravimetric analysis (TGA), transmission electron microscopy (TEM), atomic force microscopy (AFM), and $\mathrm{pH}$-varied zeta potential analyses. The Mica platelets, consisting of ionic charges on its surface (with $\equiv \mathrm{SiO}^{-} \mathrm{Na}^{+}$functionalities), were hydrophilic, dispersible in water, and estimated to be approximately $300-1000$ and $1 \mathrm{~nm}$ in thickness.

Self-Assemblies of Mica Platelets to Rod-Like and Dendrite Morphologies. A suspension of mica platelet 5 to $10 \mathrm{wt}$ $\%$ in water was placed in a beaker and than subjected to controlled dehydration in an $80^{\circ} \mathrm{C}$ over a period of $8 \mathrm{~h}$. The residue solid materials were analyzed by field emission-scanning electron microscopy (FE-SEM). Subsequently, the primary material $(0.1 \mathrm{~g})$ was further suspended in water in a $10 \mathrm{~mL}$ test tube and agitated by ultrasonic treatment in a water bath for 1 or $2 \mathrm{~h}$. The water suspension was deposited onto a carbon-coated copper grid, dried at ambient temperature and analyzed by TEM.

Characterization. The X-ray powder diffraction (XRD) was performed on a Schimadzu SD-D1 diffractometer with a $\mathrm{Cu}$ target $(\lambda=1.5405 \AA)$ at a generator voltage of $35 \mathrm{kV}$, a generator current of $30 \mathrm{~mA}$, and a scanning rate of $2 \% \mathrm{~min}$. The $d$ spacing $(n=1)$ was assigned on the basis of Bragg's equation $(\mathrm{n} \lambda=2 d \sin \theta)$. The organic/mica platelets fractions were measured by the decomposition curve of thermal gravimetric analysis (TGA), on a Perkin-Elmer Pyris 1 model. The weight of the organic component was estimated by TGA analysis. After the temperature was raised from 100 to $850{ }^{\circ} \mathrm{C}$ at the rate of $10^{\circ} \mathrm{C} / \mathrm{min}$ in air, the percentage weight lost is attributable to the organic component. Transmission electron microscopy (TEM) was performed on a Zeiss EM 902A operated at $80 \mathrm{kV}$. A suspension of the Mica sample $\left(10^{-1}\right.$ and $10^{-3} \mathrm{wt} \%$ ) in deionized water was deposited onto a carboncoated copper grid and dried at ambient temperature. The atomic force microscopy (AFM) was performed by a SPA-400HV with an SPI3800N controller (Seiko Instruments Industry Co., Ltd.). The cantilever used was fabricated from $\mathrm{Si}$ with a spring constant of $13 \mathrm{~N} / \mathrm{m}$ and a resonance frequency of $139 \mathrm{kHz}$. AFM is used to analyze fragile samples without damaging samples during the scans. The uniformity and cleanliness of the glass substrates were confirmed before coating with the Mica samples. AFM samples were prepared by dispersing the exfoliated mica platelets in deionized water at $10^{-3} \mathrm{wt} \%$ concentrations and spin-coated on glass surface at a spinning rate of $1500 \mathrm{rpm}$ for $30 \mathrm{~s}$. After spin-coating, the specimen was heated at applicable temperature for $10 \mathrm{~h}$ and then subjected to a vacuum for $24 \mathrm{~h}$ for removing water. A ZetaPlus zetameter (Brookhaven Instrument Corp., NJ) was used for characterizing the ionic property of the Mica. The zeta potentials of the pristine mica and the exfoliated Mica platelets in aqueous suspension of $0.01 \mathrm{wt} \%$ concentration were measured in the $\mathrm{pH}$ range from 2 to 11 . The background $\mathrm{pH}$ buffer solution from 2 to 4 was adjusted by $\mathrm{H}_{3} \mathrm{PO}_{4}$ and $\mathrm{KH}_{2} \mathrm{PO}_{4}$, from 5 to 8 by $\mathrm{KH}_{2} \mathrm{PO}_{4}$ and $\mathrm{Na}_{2} \mathrm{HPO}_{4}$, and from 9 to 11 by $\mathrm{Na}_{2} \mathrm{HPO}_{4}$ and $\mathrm{Na}_{3} \mathrm{PO}_{4}$, in each case at a concentration of $0.1-0.2 \mathrm{M}$. After the addition of Mica samples, the suspension $\mathrm{pH}$ was further adjusted to the desired value by adding $0.5 \mathrm{M} \mathrm{NaOH}$ or $\mathrm{HCl}$. The zeta potential was measured in the solution with an ionic strength of $0.2 .{ }^{35}$ Field emissionscanning electron microscopy (FE-SEM) was performed on a JEOL JSM-6700F SEM system. The samples were prepared by spreading onto a glass plate surface and evaporating until dryness in an oven at $80^{\circ} \mathrm{C}$ for $8 \mathrm{~h}$. The samples were coated with $\mathrm{Au}$ before the FE-SEM measurements. An ultrasonic vibrator (LEO; LEO-1502S) was operated at $150 \mathrm{~W}$ and 40 $\mathrm{KHz}$.

\section{Results and Discussion}

Characterization of the Exfoliated Mica Silicate Platelets by TEM and AFM. The random form of the Mica silicate platelets can be dispersed well in water and observed by using TEM analysis, as shown in Figure 1. By comparison, the pristine mica before the process of exfoliation is shown as aggregates in water (Supporting Information Figure S1). The finely dispersed Mica platelets of different concentrations were airdried on a TEM copper grid. The platelets are shown to have a polygon or circular shape with a polydisperse size of approximate $300-1000 \mathrm{~nm}$ in diameter. The micrographs allow the first time observation for the shape of individual platelets. In order to estimate the thickness of these platelets, we chose AFM for the detailed surface analysis. By examining the topographic image (Figure 2), we further observed the selfassembly of these thin platelets on a glass substrate after the water evaporation. The topographical contrast shows the uniformity of its structure with an estimated $300-1000 \mathrm{~nm}$ in dimension and approximately $1 \mathrm{~nm}$ in thickness, consistent with the dimension revealed previously.

Physical Properties of the Mica Platelets. The ionic charges on the silicate Mica surface were characterized by measuring their zeta potential against $\mathrm{pH}$ values. For the comparison, both the pristine Mica clay and exfoliated platelets were measured by varying the $\mathrm{pH}$ range from 2 to 11 (Figure 3). The pristine Mica suspension in water at a concentration of $0.01 \mathrm{wt} \%$ is less affected by the $\mathrm{pH}$ environment. There was no significant change above $\mathrm{pH} 8$, but a slight deviation at the low $\mathrm{pH}$ from 2 to 8 . Similar trend for the synthetic mica clay was reported. ${ }^{36}$ In contrast, it is observed that the random Mica demonstrates a tremendous change from +62 to $-61 \mathrm{mV}$ depending on the $\mathrm{pH}$ range from 2 to 8 . The voltage leveled off at $\mathrm{pH}$ above 8 , with an isoeletric point (IEP) at $\mathrm{pH}$ 6.5. The physical appearance of these Mica slurries in $0.01 \mathrm{wt} \%$ was shown to be a fine dispersion when the $\mathrm{pH}>$ IEP, but coagulated at $\mathrm{pH}<$ IEP, corresponding to the zeta potential transition. The phenomenon of $\mathrm{pH}$-dependent zeta potentials may be explained by the Mica platelet surface containing two different types of silicate 

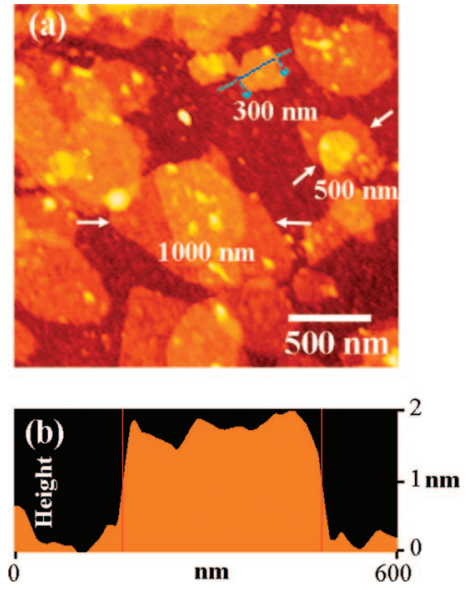

Figure 2. AFM micrographs of individual mica platelets suspended in water $\left(10^{-3} \mathrm{wt} \%\right)$ and dried at ambient temperature on glass: (a) topographical for platelet dimension $(300-1000 \mathrm{~nm})$ and (b) height image for platelet thickness (approximately $1 \mathrm{~nm}$ ).

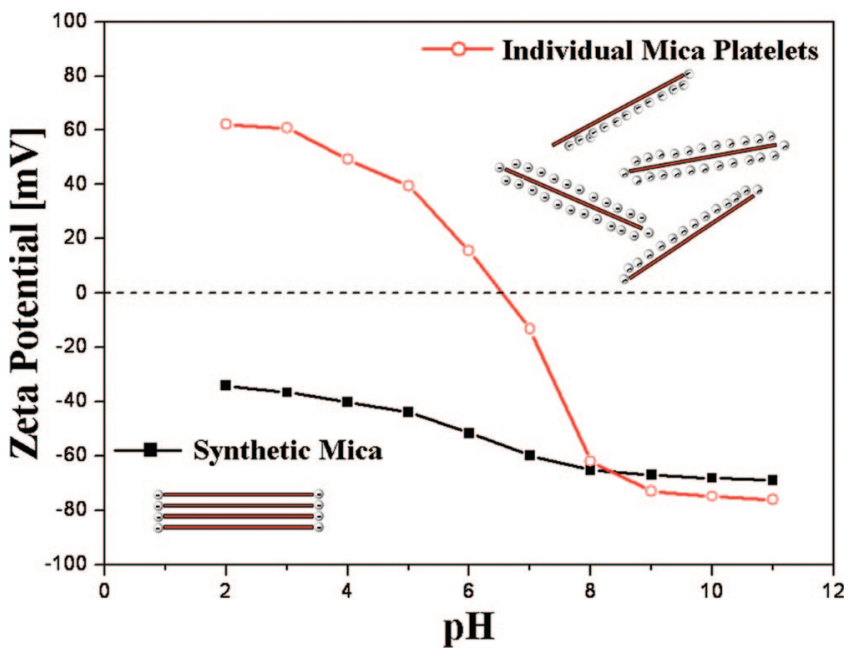

Figure 3. $\mathrm{pH}$ dependence of the zeta potentials; - $\mathbf{n}$ - pristine Mica and $-\mathrm{O}$ - individual mica platelets $(0.01 \mathrm{wt} \%)$.

hydroxyl functionalities, which originally existed but buried within the layered structure.

Self-Assembly into Rod-Like Microstructures. The individual Mica platelets consisting of a high aspect-ratio geometric shape and dense ionic charges have a tendency for selfassembling. Mica platelets in the concentrations of 5 or $10 \mathrm{wt}$ $\%$ in water may be evaporated at $80^{\circ} \mathrm{C}$ to afford solids in powder form. The FE-SEM micrographs in Figure 4, panels a and $b$, exhibit the morphologies of $5 \mathrm{wt} \%$ of this Mica powder, showing a rod-like microstructure at $20 \mu \mathrm{m}$ in length and $300-1000 \mathrm{~nm}$ in width. In contrast, the suspension at the higher concentration (10 wt \% Mica in water) tended to self-align into short arrays with the dimension of $3 \mu \mathrm{m}$ in length and 300-1000 $\mathrm{nm}$ in width (Figure 4, panels $\mathrm{c}$ and d). The control experiment demonstrated that the aqueous suspension of pristine mica is amorphous or in an irregular aggregated morphology after water evaporation (Figure 4, panels e and f).

The self-assembling mechanism can be explained by the intensive forces of platelet face-to-face piling through Coulombic attraction. In other words, the individual mica platelets associate into rod-like microstructures with uniform width and varying lengths that depending on the concentration of the original aqueous suspension. These self-assembled solid powders were measured by XRD to have a regular $14.6 \AA$ basal spacing
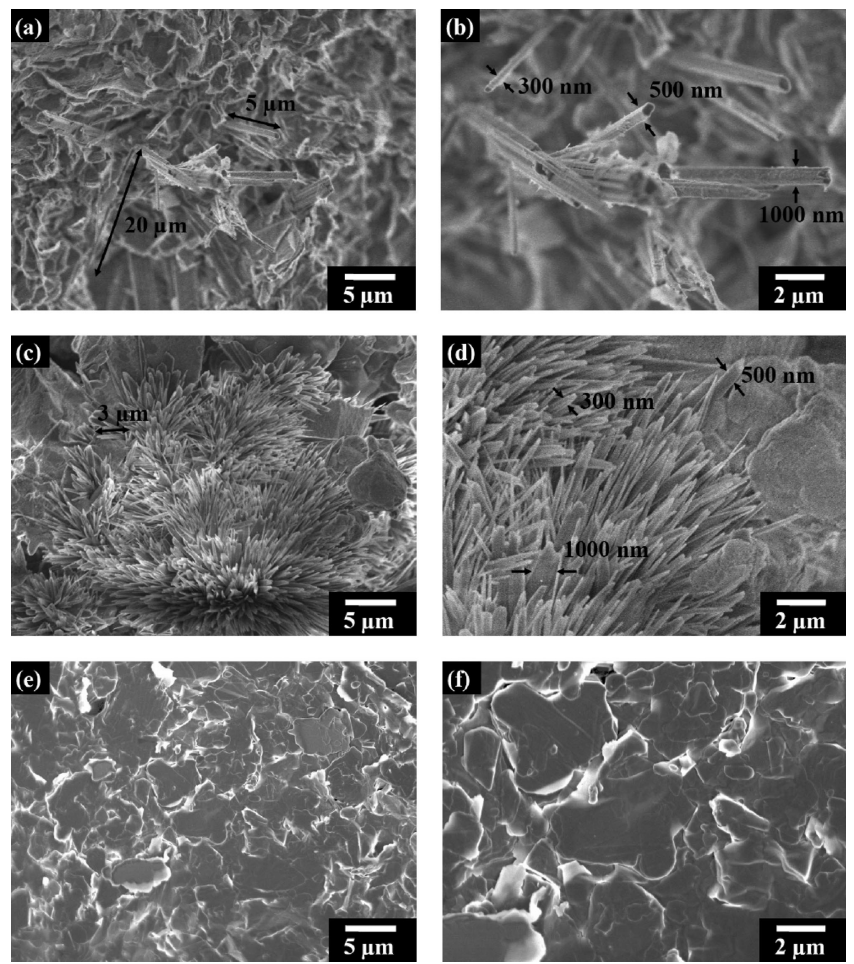

Figure 4. FE-SEM micrographs of self-assembly ( $a$ and b) from $5 \mathrm{wt}$ $\%$ of random mica platelets in water, at different magnifications, (c and d) from 10 wt \% random mica platelets after water evaporation, and (e and $\mathrm{f}$ ) from $5 \mathrm{wt} \%$ of pristine Mica suspension under the conditions of water removal at $80^{\circ} \mathrm{C}$.

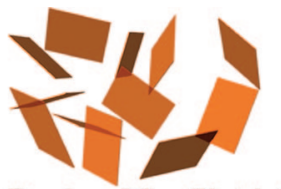

Random Mica Platelets

Average $300-1000 \mathrm{~nm}$ in Width and $1 \mathrm{~nm}$ in Thickness Platelet Piling

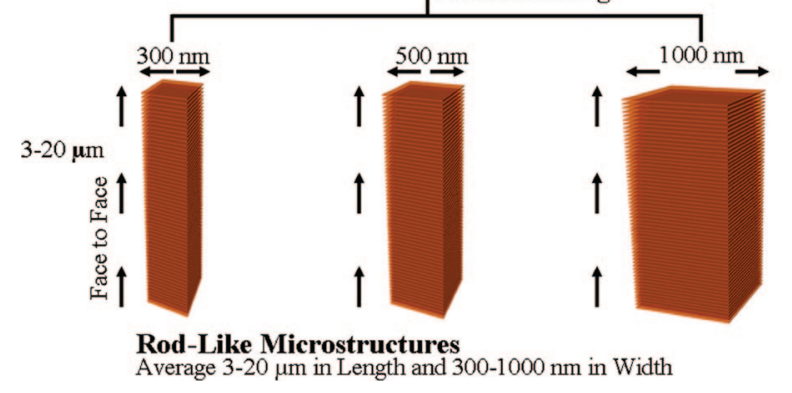

Figure 5. Conceptual diagrams of polydisperse platelets under selfassembling into rods of different diameters but with a high uniformity in individuals.

(Supporting Information Figure S2), revealing the self-piling occurrence from the random state into highly regular microstructures. Assuming the rod-like microstructures are piled up from the individual platelets in different dimension in the range of $300-1000 \mathrm{~nm}$, it can be then estimated that the rod length in one micrometer is piled up by approximately 650 platelets (or $1.0 \mu \mathrm{m} / 1.46 \mathrm{~nm}$ of XRD $d$ spacing). The observed 3-20 $\mu \mathrm{m}$ rod morphologies could actually contain as many as 1950-13000 platelets for each individual rod. The formation of rod-like microstructures is controlled by the tremendous force of ionic charge attraction on silicate surface as well as the extreme thinness of the platelets. The observation of a uniform diameter width in the individual rods suggests that the poly- 

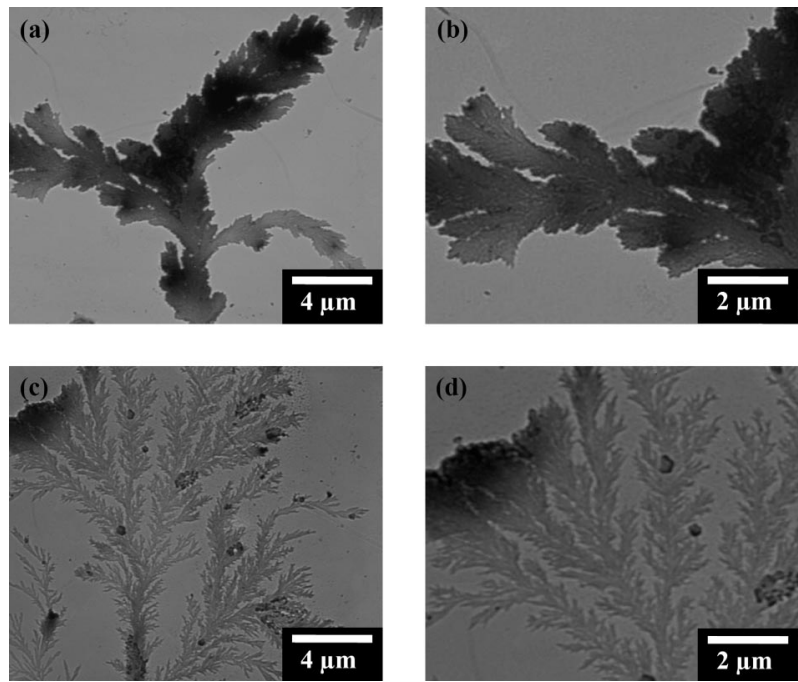

Figure 6. TEM micrographs of the fern-leaf dendrites after (a and b) $1 \mathrm{~h}$ and (c and d) $2 \mathrm{~h}$ ultrasonic treatment and dried on copper grid.

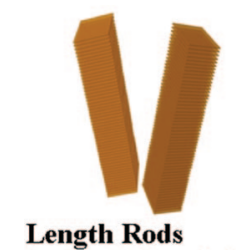

Average 3-20 $\mu \mathrm{m}$ in Length and $300-1000 \mathrm{~nm}$ in Width

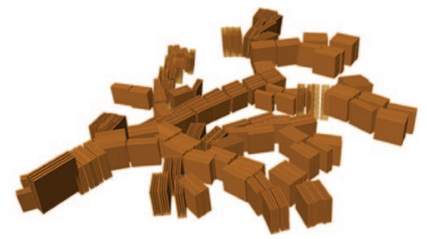

Fern-Leaf Dendrites Re-Stacking to Free Sites

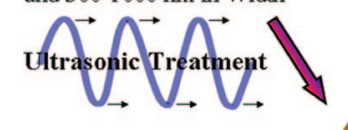

Re-Stacking

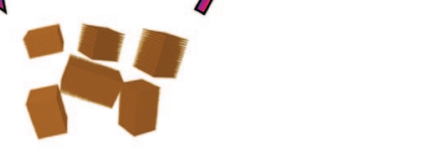

\section{Rearrangement into Short-Rod Fractures}

Figure 7. Conceptual diagrams for the transformation of lengthy rods into fern-leaf dendrites under ultrasonic treatment via fracturing and restacking.

disperse platelets seem to aggregate in a selective manner. In other words, platelets with the similar sizes prefer to find each other to form the same rod. Although the driving force is not well understood, the platelets appeared to organize themselves in a manner minimizing the excess surface energy of the platelets that could only be achieved by selecting the similar size of platelets to form an individual rod as schematically described in Figure 5.

Rearrangement of Rod-Like Arrays into Fern-Leaf Dendrites. The strong force associated with platelet piling, which in turn increases the rod length, is further evidenced from the rearrangement of short rod fractures. The rod-like self-assemblies may further undergo a fracture/rearrangement process into different morphologies. By simply dispersing the samples in water at the concentration of $1 \mathrm{wt} \%$ and then agitating by ultrasonic vibration for 1 and $2 \mathrm{~h}$, the new morphology is shown by TEM in Figure 6. The images of fern-leaf dendrites are derived from the lengthy rods: microstructures were fractured by ultrasonic energy and restacked. The formation of these dendrites during the ultrasonic treatment of a $1 \mathrm{~h}$ period, an apparent coagulation first occurred (Figure 6, panels a and b). After a continuous energy treatment for $2 \mathrm{~h}$, finer dendrites with regular branching and a leaf-like shape were observed in Figure 6 , panels $\mathrm{c}$ and $\mathrm{d}$. The explanation for the fracturing and

restacking of primary rods into fern-leaf dendrites is conceptually illustrated in Figure 7. During the ultrasonic energy treatment, the rods were broken into short fractures and rearranged into branched dendrites.

\section{Conclusion}

In conclusion, the individual platelets, with surface ionic charges and of a thin platelet shape in the dimension of 300-1000 nm diameter and $1 \mathrm{~nm}$ thickness, were able to selfassemble in a hierarchical manner. The platelets enabled to selfassociate into rod-like microstructures which could be fractured into smaller pieces under the ultrasonic vibration and subsequent self-stackinged into dendrite-like arrays. The proposed mechanism involves the charge attraction force between platelets $\left(\equiv \mathrm{SiO}^{-} \mathrm{Na}^{+}\right.$) and perhaps also size selectivity for forming the hierarchical self-assemblies.

Acknowledgment. We acknowledge financial support from National Science Council (NSC) of Taiwan and partially from Ministry of Economic Affairs (Taiwan).

Supporting Information Available: TEM micrographs of pristine Mica, and XRD analysis of the Mica silicate clay. This material is available free of charge via the Internet at http:// pubs.acs.org.

\section{References and Notes}

(1) Alexandre, M.; Dubois, P. Mater. Sci. Eng. 2000, $28,1$.

(2) Ray, S. S.; Okamoto, M. Prog. Polym. Sci. 2003, 28, 1539.

(3) Eckle, M.; Decher, G. Nano Lett. 2001, 1, 45.

(4) Kagan, C. R.; Mitzi, D. B.; Dimitrakopoulos, C. D. Science 1999, 286,945

(5) Choy, J. H.; Kwak, S. Y.; Jeong, Y. J.; Park, J. S. Angew. Chem., Int. Ed. 2000, 39, 4041.

(6) Cristofaro, A. D.; Violante, A. Appl. Clay Sci. 2001, 19, 59.

(7) Edmondson, M. J.; Zhou, W.; Sieber, S. A.; Jones, I. P.; Gameson, I.; Anderson, P. A.; Edwards, P. P. Adv. Mater. 2001, 13, 1608.

(8) Wang, Y. W.; Zhang, L. D.; Meng, G. W.; Peng, X. S.; Jin, Y. X.; Zhang, J. J. Phys. Chem. B 2002, 106, 2502.

(9) Li, Y.; Bando, Y.; Golberg, D. Adv. Mater. 2003, 15, 581.

(10) Xiong, Y.; Xie, Y.; Wu, C.; Yang, J.; Li, Z.; Xu, F. Adv. Mater. $\mathbf{2 0 0 3}, 15,405$.

(11) Xia, Y.; Yang, P.; Sun, Y.; Wu, Y.; Mayers, B.; Gates, B.; Yin, Y.; Kim, F.; Yan, H. Adv. Mater. 2003, 15, 353.

(12) Li, M.; Schnablegger, H.; Mann, S. Nature 1999, 402, 393.

(13) Hartgerink, J. D.; Beniash, E.; Stupp, S. I. Science 2001, 294, 1684.

(14) Jenekhe, S. A.; Chen, X. L. Science 1999, 283, 372.

(15) Clark, T. D.; Ferrigno, R.; Tien, J.; Paul, K. E.; Whitesides, G. M. J. Am. Chem. Soc. 2002, 124, 5419.

(16) Chopra, K. L. Thin Film Phenomena; McGraw-Hill: New York, 1969.

(17) Cui, Y.; Bjork, M. T.; Liddle, J. A.; Sonnichsen, C.; Boussert, B.; Alivisatos, A. P. Nano Lett. 2004, 4, 1093.

(18) Mikrajuddin; Iskandar, F.; Okuyama, K. Adv. Mater. 2002, 14, 930.

(19) Usuki, A.; Hasegawa, N.; Kadoura, H.; Okamoto, T. Nano Lett. 2001, 1, 271.

(20) Pinnavaia, T. J. Science 1983, 220, 365.

(21) Vaia, R. A.; Teukolsky, R. K.; Giannelis, E. P. Chem. Mater. 1994, 6, 1017.

(22) Klapyta, Z.; Fujita, T.; Iyi, N. Appl. Clay Sci. 2001, 19, 5.

(23) Ijdo, W. L.; Pinnavaia, T. J. Chem. Mater. 1999, 11, 3227.

(24) Imai, Y.; Nishimura, S.; Abe, E.; Tateyama, H.; Abiko, A.;

Yamaguchi, A.; Aoyama, T.; Taguchi, H. Chem. Mater. 2002, 14, 477.

(25) Fu, X.; Qutubuddin, S. Polymer 2001, 42, 807.

(26) Sepehr, M.; Utracki, L. A.; Zheng, X.; Wilkie, C. A. Polymer 2005, $46,11557$.

(27) Theng, B. K. G. Formation and properties of clay-polymer complexes; Elsevier: New York, 1979.

(28) Olphen, H. V. Clay colloid chemistry, 2nd ed.; John Wiley \& Sons: New York, 1997.

(29) Fornes, T. D.; Hunter, D. L.; Paul, D. R. Macromolecules 2004, 37, 1793.

(30) Lin, J. J.; Chen, Y. M. Langmuir 2004, 20, 4261.

(31) Chiu, C. W.; Chu, C. C.; Cheng, W. T.; Lin, J. J. Eur. Polym. J. 2008, 44, 628 . 
(32) Chiu, C. W.; Cheng, W. T.; Wang, Y. P.; Lin, J. J. Ind. Eng. Chem. Res. 2007, 46, 7384.

(33) Lin, J. J.; Chen, Y. M.; Tsai, W. C.; Chiu, C. W. J. Phys. Chem. C 2008, 112, 9637.

(34) Lin, J. J.; Chu, C. C.; Chiang, M. L.; Tsai, W. C. J. Phys. Chem. $B$ 2006, 110, 18115 .
(35) Lide, D. R. CRC Handbook of Chemistry and Physics, 82nd ed.; CRC Press, Inc.: Boca Raton, FL, 2001.

(36) Tateyama, H.; Nishimura, S.; Tsunematsu, K.; Kimura, M. Clay Sci. 1992, 8, 241.

JP806768V 